\title{
Representación de la prostitución inmigrante en la prensa. El caso de las prostitutas del barrio del Raval de Barcelona ${ }^{1}$
}

\author{
Julia BrosA HERnÁNDEZ \\ Universitat Pompeu Fabra \\ juliabrosah@gmail.com \\ Pilar MEDINA BRAVO \\ Universitat Pompeu Fabra \\ pilar.medina@upf.edu
}

Recibido: $14 / 10 / 2011$

Aceptado: 16/04/2012

\section{Resumen}

El 1 de septiembre del 2009, el diario El País publicaba en portada las imágenes de prostitutas practicando sexo en el mercado de la Boqueria de Barclona. A raíz de estas fotografías, prensa y televisiones autonómicas y estatales se hicieron eco de la noticia. El presente estudio se centra en el análisis de las noticias publicadas por los diarios El País y La Vanguardia para estudiar qué imagen se proyecta de las mujeres que se dedican al trabajo sexual. Los resultados apuntan a una doble estigmatización de la mujer que se dedica a la prostitución, al encajarla en las etiquetas de víctimas y, a la vez, culpables

Palabras clave: Prostitución, inmigración, prensa, El País, La Vanguardia

\section{Representation of immigrant prostitution in the press. The case of the prostitutes in the Raval district of Barcelona}

\begin{abstract}
On September 1, 2009, El Pais newspaper published front-page pictures of prostitutes having sex in the Boqueria market in Barcelona. Following these photographs, newspapers and regional television and state echoed the news. This study focuses on the analysis of the news published by newspapers El Pais and La Vanguardia, to consider what image is projected of women engaged in sex work. The results point to a double stigma of women dedicated to prostitution, to fit into the labels of victims and, at the same time, guilty.
\end{abstract}

Keywords: Prostitution, Immigration, Press, El País, La Vanguardia

\section{Referencia normalizada}

BROSA HERNÁNDEZ, Julia y MEDINA BRAVO, Pilar (2012): "Representación de la prostitución inmigrante en la prensa. El caso de las prostitutas del barrio del Raval de Barcelona". Estudios sobre el mensaje periodístico. Vol. 18, núm. 1, págs.: 259-273. Madrid, Servicio de Publicaciones de la Universidad Complutense.

Sumario: 1. Introducción. 2. Marco teórico. 2.1 Discurso mediático sobre las mujeres inmigrantes que ejercen prostitución: la triple discriminación. 2.2. Las prostitutas: mujeres desviadas de la norma. 3. Método. 3.1. Planilla de análisis. 3.2. Muestra: criterios de selección. 4. Resultados. 4.1. Titulares de $E l$ País. 4.2. Titulares de La Vanguardia. 4.3. Definición de inmigrante/prostituta. 4.4. Acciones realizadas por las inmigrantes/prostitutas. 4.5. Acciones realizadas sobre las inmigrantes prostitutas. 5. Conclusiones. 6. Referencias bibliográficas. 7. Anexo 1: ejemplos aplicados de ficha analítica.

1 Este artículo tiene su origen en la investigación de Julia Brosa, tutelada por Pilar Medina, dentro del programa de posgrado del Departamento de Comunicación de la Universitat Pompeu Fabra, 2010. 


\section{Introducción}

"Nos faltaron al respecto generalizando y hablando de nosotras como si no fuéramos personas. Blancas, negras, legales o ilegales. Somos mujeres y somos personas" (Tania, 10/09/2009).

Con estas palabras, Tania, una mujer que se dedica a ejercer la prostitución en el barrio del Raval de Barcelona, denunciaba el trato recibido por los medios de comunicación en una rueda de prensa el día 10 de septiembre del 2009. Una rueda de prensa a la que también comparecieron otras mujeres para pedir respeto y facilidades para poder trabajar en unas condiciones dignas y no verse obligadas a ejercer en la calle. El diario El País las había situado en el ojo del huracán al publicar en portada unas imágenes de mujeres practicando sexo explícito en el mercado de la Boqueria de Barcelona. Las fotografias situaron a estas mujeres en el punto de mira de la sociedad durante más de diez días, provocando un auténtico revuelo mediático y poniendo sobre la mesa la necesidad de abordar el debate sobre la regulación de la prostitución.

El caso de las fotografías del Raval es un caso paradigmático sobre como un medio de comunicación tiene la fuerza de situar una temática concreta en el centro del debate público. Al pasar a ser el centro de la agenda mediática del momento, también pasó a ser tema de la agenda política y las diferentes administraciones se vieron obligadas a reaccionar. Así, por ejemplo, el Ayuntamiento de Barcelona pasó a avisar que la práctica de sexo en la calle vulneraba la ordenanza de civismo y las imágenes eran la prueba -según señalaban también algunos medios de comunicación- de la degradación del barrio. Para la Generalitat, supuso atender el tema de la prostitución no sólo en el Raval sino en otros puntos del territorio catalán en los que las mujeres ejercían la prostitución a pie de carretera, en las salidas de las grandes ciudades y, en general, en el espacio público. Lo que había empezado como un problema local en un barrio barcelonés acabó extendiéndose -a través de los medios- en un tema que se podía extrapolar a cualquier parte del territorio catalán; en boca del consejero de Política territorial y obras públicas, Joaquim Nadal, salió diciendo que no se podía legislar a golpe "de titular" y que se seguiría trabajando en la línea de erradicar las mafias que trafican con mujeres para su explotación sexual con los instrumentos que se disponen desde los ayuntamientos, la Generalitat y el Estado. Y, evidentemente, el Estado también tenía algo que decir puesto que es competencia suya emitir algún tipo de regulación sobre el tema de la prostitución. El presidente de gobierno, José Luis Rodríguez Zapatero, mostró su "rechazo" hacia la prostitución, y reconoció que las imágenes captadas a las calles de Barcelona habían causado un "malestar notable". Y en el congreso, el grupo de IU, ICV y ERC aprovechó la circunstancia promovida por los medios para volver a poner encima de la mesa la proposición no de ley para regular la prostitución, registrada en abril del 2008, que instaba al Gobierno a regular la prostitución voluntaria incluyendo el derecho a la seguridad social, a la sindicación y a la negociación colectiva, acceso a servicios sanitarios y de formación, mejora de los espacios y condiciones de trabajo y una fiscalidad propia. Pedían abordar el debate de la prostitución sin prejuicios ni tabúes, y teniendo en cuenta toda la complejidad que supone. 


\title{
2. Marco teórico
}

\subsection{Discurso mediático sobre las mujeres inmigrantes que ejercen prostitución: la triple discriminación}

\author{
"Todo lo que sé es porque lo he leído en la prensa"
} (McComBs, 2006: 23)

Tal y como defiende McComBs (2004: 24) "los editores y directores informativos, con su elección día a día y su despliegue de informaciones, dirigen nuestra atención e influyen en nuestra percepción de cuáles son los temas más importantes del día. Esta capacidad para influir en la relevancia de las cuestiones del repertorio público es lo que se ha dado en llamar la fijación de la agenda por parte de los medios de comunicación". Pero no sólo destacan unos temas por encima de otros, sino que también dirigen el debate generado: "Los medios informativos pueden establecer la agenda del debate y del pensamiento públicos" (McComBs, 2004: 25). La opinión pública puede tener opinión sobre muchos temas, pero sólo algunos adquieren la suficiente importancia como para que valga la pena tengan una opinión al respecto. Y aquí es donde entran en juego los medios de comunicación cuando, de manera deliberada o no, seleccionan y destacan un conjunto de temáticas que serán las noticias más relevantes del momento.

Al hablar de una triple discriminación en el discurso mediático, nos estamos refiriendo a de qué manera en la mujer inmigrante que se dedica a la prostitución sobrevuela la discriminación por ser mujer (debido a la infrarrepresentación de las mujeres en los medios de comunicación ${ }^{2}$ ), la imagen estereotipada y tópica que se tiene sobre la inmigración (GIRÓ y JARQUe, 2006; IgARTÚA, et al., 2004; MuÑIZ \& IGARTÚA, 2004; Pedone, 2001; Rodrigo Alsina, 2006; DiJK, 2006), y, por último, la estigmatización que recibe el trabajo sexual.

En el caso concreto de la prostitución, acostumbra a aparecer cuando se habla de las actuaciones policiales que desarticulan redes de prostitución ilegales por lo que queda fijada la imagen de asociar prostitución a conflicto y a problema social. Pero no nos olvidemos de que la prostitución también está presente de manera sutil en prácticamente todos los diarios de más tirada del estado español en las páginas de contactos. Se trata de una realidad que no está por el momento ni en la agenda mediática ni en la agenda política, aunque el diario Publico (que no acepta páginas de contacto) denunciaba, justamente a raíz de la publicación de las fotografías que nos ocupan, el volumen de ingresos que suponía para El País la incorporación de este tipo de publicidad: más de cinco millones de euros. La denuncia también recordaba el cálculo realizado por una comisión parlamentaria a lo largo del año 2007, según el cual los diarios españoles ganaban un total de 40 millones de euros anuales con este tipo de anuncios, siendo precisamente El País el diario que más se embolsaba a nivel estatal, por encima de El Mundo y las cabeceras del Grupo Vocento que se repartían 10 millones $^{3}$.

${ }^{2}$ Consultar: http://www.mujer.migualdad.es/mujer/mujeres/cifras/index.htm

${ }^{3}$ Consultar en: http://www.publico.es/espana/250085/gran/negocio/hipocrita/prostitucion 
Como vemos, la prostitución tiene muchas presentaciones. Laura Ma Agustín (2004: 28) nos recuerda las múltiples caras de la industria del sexo en el estado español, que incluye burdeles, casas de citas, clubes por la noche, bares, cervecerías, discotecas, cabarets, saunas, o las llamadas call-girls. Por ello considera que sería más apropiado 'hablar de diferentes tipos de trabajos sexuales, que van más allá de la prostitución'. Y por esta misma razón, también denuncia que sea la prostitución en la calle la más visibilizada por los medios de comunicación cuando se trata de la menos frecuente.

Para Juliano $(2005,2001)$, la discriminación social de la mujer que ejerce la prostitución se basa en la imagen distorsionada que ofrecen los medios de comunicación, pero también diferentes ámbitos académicos y sociales. La invisibilidad en los medios de comunicación de la mujer inmigrante contrasta con la hipervisibilidad de la trabajadora sexual inmigrante cuando, en realidad, son un colectivo no muy numeroso. El tratamiento distorsionado de sus problemas, el hecho de subrayar continuamente la diferencia frente a otros colectivos sin mostrar lo que tienen en común, la presentación sistemática como víctimas engañadas sin proyecto propio constituyen elementos que configuran un ejemplo de violencia simbólica ejercido sobre estas mujeres y que va a servir de justificación de otros tipos de violencia.

\subsection{Las prostitutas: mujeres desviadas de la norma}

Pese a la incorporación de la mujer a la esfera pública, aún podemos comprobar la sombra potente del patriarcado en la ausencia en nuestra sociedad de modelos positivos de mujeres que transgreden las normas y pautas tradicionales. "Todas las mujeres que deciden vivir según modelos de conducta diferentes de los establecidos como normales por el sistema patriarcal tradicional sufren, además de los castigos legales y sociales previstos para la infracción, una desvalorización y/o estigmatización" (JULIANO, 2005: 7). Por esto, y siguiendo a la misma autora, las lesbianas, las madres solteras, separadas o monoparentales, mujeres conflictivas o cuestionadoras del orden establecido, las que prestan servicios sexuales remunerados o las que trabajan en la industria del sexo, son colectivos que sufren en diferente grado esta estigmatización social. Son las que Juliano (2005) nombra "desviadas de las normas", ovejas negras que han perdido el camino. Su principal castigo: la violencia simbólica de la discriminación, aunque a menudo también conlleva violencia material hasta el maltrato.

Ya en el 2001, HolgADO afirmaba en un artículo que "el colectivo de mujeres inmigrantes que sufre mayor discriminación legal y maltrato social son las trabajadoras sexuales. En este sentido, en los últimos años los medios de comunicación se han encargado de fomentar la alarma social, al construir la imagen de la mujer inmigrada prostituta con tremenda superficialidad, sesgo moralista demasiado rancio y fuertes dosis de sensacionalismo y falsedad. Por primera vez, las mujeres inmigrantes acaparan las portadas de los diarios, son objeto de reportajes especiales y tema del día en los espacios televisivos, promoviendo la asunción de la ecuación 'mujer inmigrante igual a prostituta'. Por supuesto, nada que ver cono la complejísima realidad y multidimensionalidad de este fenómeno" (Holgado, 2001).

En este mismo sentido, Juliano (1998: 59) apuntaba que "las inmigrantes extracomunitarias encuentran en la sociedad de acogida trabajos en que resultan discriminadas 
por razones de género, precisamente porque son los lugares de trabajo tradicionalmente femeninos que liberan las mujeres españolas. Las inmigrantes heredan así la discriminación salarial, al mismo tiempo que se ven empujadas a otras actividades consideradas indignas o peligrosas como la prostitución. Este tipo de trabajo ya ha sido desvalorizado previamente en tanto que femenino, como su connotación religiosa de pecado e impureza". Son discriminaciones que comparten la idea de considerar a la mujer como ser vulnerable, carente de la posibilidad de escoger. Cuidando el riesgo de las generalizaciones, tanto Juliano (2005) como Agustín $(2004,2006)$ coinciden en remarcar que, más a menudo de lo que considera la población, la decisión de dedicarse a la prostitución se ha tomado libremente y no ha habido engaño. Más concretamente, AGUSTín (2006) señala que las investigaciones sobre las migraciones transnacionales mantienen silencio sobre las personas que venden sexo, como si fuera un asunto que no pudiera ser mencionado. Y no puede ser mencionado precisamente porque se parte del prejuicio de que el cuerpo de mujer es sexualmente vulnerable e indefenso: "La teoría de que el cuerpo femenino está dispuesto a ser dañado sostiene que el alma o el verdadero yo es alienado cuando se mantienen relaciones sexuales fuera del contexto del amor, y que las mujeres quedan irremediablemente heridas por esa experiencia" (AGUSTín, 2006: 78). Pero la realidad es que algunas se sienten efectivamente así, y otras no, lo que nos lleva a concluir que no se puede pretender una respuesta unitaria en la experiencia y el valor atribuido al trabajo sexual. En cualquier caso, apunta Agustín, incluso las personas a quienes no les gusta vender sexo dicen que es mejor que muchas otras opciones que tampoco les gustan. Sin embargo, el tabú y los prejuicios se mantienen con fuerza e impiden tener en cuenta la multiplicidad de situaciones y experiencias que giran en torno a la prostitución. Aunque, como hemos señalado anteriormente, hay un abanico amplio de motivaciones y experiencias personales detrás de cada prostituta, se mantiene el estereotipo de la prostituta considerada como víctima de sí misma o de los demás, una perdedora a la que hay que salvar. Es contra estereotipos victimistas de este estilo contra los que se levantan voces como la de Carla Corso, ex trabajadora sexual y co-fundadora del Comité Italiano a favor de los Derechos Civiles de las Prostitutas cuando defiende: 'Yo no soy víctima de nadie. Evidentemente he sufrido miedo las dificultadas de la vida, pero como todos. No quiero ser una víctima de estos sufrimientos: los combato y quiero salir victoriosa" (HoLGADO, 2004)

Lo que denunciaba Corso tiene que ver con el ordenamiento sexista que dictamina qué es lo esperable en una mujer y qué será castigado. Uno de los principios de este ordenamiento social establece que las mujeres sólo deben dar sexo a cambio de amor romántico, pero no a cambio de dinero, algo que merece miradas de desprecio y/o compasión. Como apunta Juliano (2005), el crimen no es el acto sexual en sí, sino pedir dinero a cambio, lo que implica una estigmatización por razones morales. La etiqueta de la mujer que se dedica a la prostitución tiene más que ver con la trasgresión como mujer de los códigos discriminatorios de género que con el comercio sexual real (HoLGADO, 2004), y el mantenimiento del prejuicio contra este colectivo aumenta su vulnerabilidad legal e institucional: "Si no se tienen derechos, se depende de la buena voluntad de los demás. Las personas a las que se protege pierden autonomía y capacidad de organización. Sólo una cobertura legal apropiada permite el empoderamiento [...] Si en la sociedad tradicional a las prostitutas se les negaba el aprecio so- 
cial porque no cumplían los requisitos de virtud, es decir, eran pecadoras, me temo que en la sociedad actual les estamos negando nuestro reconocimiento al negarles la condición de trabajadoras [...] Les estamos negando su derecho a ser reconocidas como personas con derechos y obligaciones dentro de la sociedad. Estamos en un momento en que la ética pasa por la ética laboral. Les estamos negando su condición de trabajadoras" (JULIANO, 2005:47).

Sin embargo, conviene aclarar que dentro del feminismo no se comparte la misma mirada sobre la prostitución. Frente a la postura defendida por aquellas organizaciones feministas que luchan por su despenalización para que las mujeres que ejercen la prostitución tengan garantizados sus derechos, están aquellos otros movimientos feministas que se sitúan en una posición abolicionista, el entender la prostitución como una forma privilegiada de patriarcado y una forma de esclavitud sexual que -como tal esclavitud- nunca puede ser voluntaria ni escogida libremente. Desde la posición 'despenalizadora', la postura abolicionista sólo redunda en la visión victimista y discriminatoria de las mismas mujeres a las que se pretenden salvar, al imposibilitarlas como agentes activos de su propia decisión.

\section{Método}

El presente trabajo tiene como objetivo general estudiar la representación que la prensa hace de la mujer inmigrante que ejerce la prostitución. Para ello, nos centramos en el análisis de la representación que sobre la mujer inmigrante que ejerce la prostitución realizaron los diarios El País (EP) y La Vanguardia (LV) a partir de las fotografías de portada de prostitutas practicando sexo en el mercado de la Boquería de Barcelona ( $E l$ País, 1/09/2009).

El análisis cualitativo nos permitirá comprobar si hay un discurso culpabilizador $\mathrm{y}$, por lo tanto, estigmatizador de la mujer inmigrante que ejerce la prostitución.

\subsection{Plantilla de análisis}

Para el análisis se ha seguido la "escala de Encuadres Noticiosos sobre Inmigración" (escala ENI) de IGARTÚA, et al. (2004), que plantea la organización de palabras y expresiones clave a partir de 7 categorías:
a) lugar geográfico (dónde)
b) espacios físicos (dónde)
c) espacios temporales (cuándo tiene lugar)
d) actores protagonistas de la noticia (quién, ya sean individuos o grupos
e) definición de inmigrante (cómo se define al inmigrante)
f) acciones realizadas por los inmigrantes (qué hacen los inmigrantes)
g) acciones realizadas a los inmigrantes (qué se hace a los inmigrantes).

Para los motivos de nuestro estudio, además de la adaptación de algunas de las categorías, se añadió a la ficha final la categoría de 'Titular' en la que se dejaba constancia del titular de la noticia. La ficha final resultante fue la siguiente"

${ }^{4}$ En el anexo 1 se adjuntan dos ejemplos de fichas completadas. 


\begin{tabular}{|l|l|}
\hline Titular \\
\hline Lugar geográfico & \\
\hline Espacios físicos & \\
\hline Espacios temporales & \\
\hline Actores protagonistas de la noticia & \\
\hline Definición inmigrante/prostituta & \\
\hline Acciones realizadas $p$ or las inmigrantes/prostitutas & \\
\hline Acciones realizadas $a$ los inmigrantes & \\
\hline
\end{tabular}

\subsection{Muestra: criterios de selección}

En el presente estudio se han tenido en cuenta todas las noticias, artículos de opinión y editoriales de los diarios El País (EP) y La Vanguardia (LV) comprendidos entre el día 1 de septiembre, día en que EP publicaba las imágenes de mujeres practicando sexo explícito en el mercado de la Boquería del barrio del Raval de Barcelona, y el día 11 de septiembre, esto es 11 días en total como intervalo temporal. Teniendo en cuenta los objetivos del trabajo, los días escogidos responden al periodo durante el cual EP vinculaba la prostitución con la inmigración y, por lo tanto, eran las piezas informativas que se ceñían a los requisitos para ser incluidos en nuestro análisis. Estos mismos días serán el intervalo para recoger las piezas informativas relevantes publicadas en LV. A partir del 11 de septiembre, el tema decae en EP, y el foco mediático pasó a centrarse en el debate sobre la necesidad o no de regular la prostitución y el hecho que las mujeres fueran en su mayoría inmigradas pasó a un segundo plano. Dado que el objetivo concreto se centra en el análisis de la representación que se hace de las mujeres que se dedican a la prostitución en el mercado de la Boquería, los artículos en los que no aparecía el mercado de la Boquería o la prostitución en el Raval como trasfondo fueron omitidos de este estudio.

Finalmente y teniendo en cuenta los criterios de selección de la muestra, se recopilaron un total de 18 piezas informativas que vinculaban prostitución con inmigración en EP (más 1 artículo de opinión) y 18 piezas en LV (más 2 artículos de opinión).

\section{Resultados}

Por razones obvias de espacio, el presente artículo se centra específicamente en el análisis de las siguientes categorías: titulares de El País y de La Vanguardia; definición de inmigrante/prostituta; acciones realizadas por las inmigrantes/prostitutas; y acciones realizadas sobre las inmigrantes/prostitutas.

\subsection{Titulares de El País}

Relación de titulares de El País (de 1/09/2009 a 11/09/2009): Titular 1 (T1): Mercado de sexo junto a la Boquería (01/09/2009); (T2): Un prostíbulo al aire libre (01/09/2009); (T3): Hay muchas más putas que nunca; (T4): Barcelona culpa a Interior del aumento de la prostitución (2/09/2009); (T5): No podemos ser la ciudad del sexo (2/09/2009); (T6): "Hostigar las prostitutas no es la solución", dice un agente 
(2/09/2009); (T7): La solución ha de ser transversal, y no solo policial (2/09/2009); (T8): Vecinos y tenderos reclaman regular la prostitución (2/09/2009); (T9): Luces y policía a la espera de actividad (2/09/2009); (T10): Mossos y Urbana lanzan un operativo para atajar la prostitución en el Raval (3/09/2009); (T11): El operativo policial vacía la Rambla de prostitutas y satisface a los vecinos (04/09/2009); (T12): Huída por el Eixample (03/09/2009); (T13): Saura descarta legislar sobre sexo de pago esta legislatura (04/09/2009); (T14). Interior mantendrá a los Mossos en La Rambla hasta otoño; (T15): Hago la calle por necesidad (06/09/2009); (T16): Cuatro meretrices, detenidas en una redada policial en Barcelona (06/09/2009); (T17): Nos pueden esconder bajo la alfombra, pero seguiremos existiendo (09/09/2009); y (T18): "CiU, PP y ERC se oponen a la recuperación de burdeles en el Raval" (11/09/2009)

A partir del análisis de los 18 titulares, se comprueba que los dos primeros días se hará una referencia constante al aumento de la prostitución en Barcelona (titulares 1 a 5), aunque también aparece enseguida la referencia a las posibles soluciones para reducir la prostitución o, cuanto menos, evitar el sexo en plena calle (titulares 6 a 8). Y es una de las posibles soluciones, la policial, la que ocupa los titulares de los siguientes días (titulares 9 a14), describiendo las actuaciones que llevan a término con el objetivo de atajar "la prostitución". Entre el 6 y 9 de septiembre, (titulares 15 y 17), EP coloca a las mujeres que ejercen la prostitución en el eje central del titular. A partir d e los datos, puede establecerse de qué manera los titulares dejan clara la vinculación entre prostitución y problemas.

\subsection{Titulares de La Vanguardia}

Relación de titulares de La Vanguardia (de 4/09/2009 a 11/09/2009): (T1): ¿Por qué no se acaba con esto? (04/09/2009); (T2): Ni regulada, ni prohibida: fuera de control; (T3): Mujeres sin papeles en el laberinto (04/09/2009); (T4): Hereu se compromete a sacar la prostitución de la Rambla (05/09/2009); (T5): Juego del ratón y el gato en la ronda de Sant Antoni (05/09/2009); (T6): Interior garantiza más vigilancia todo el año (05/09/2009); (T7): Desconcierto ante la prostitución (06/09/2009); (T8): Callejón sin salida; (T9): ICV se desmarca de Hereu y pide zonas de tolerancia (06/09/2009); (T10): Infructuosa redada en la Rambla contra la prostitución callejera (06/09/2009); (T11). A la carrera por Sant Antoni (06/09/2009); (T12): Los hoteleros atribuyen la degradación a la permisividad (08/09/2009); (T13): Extorsión a la nigeriana (09/09/2009); (t13): Imagen por los suelos (08/09/2009); (T14): Abismo en el Raval (08/09/2009); (T15): Las operaciones urbanísticas no han eliminado la mala vida del barrio (10/09/2009); (T16): "No son chicas de prostíbulo" (08/09/2009)

Lo primero que llama la atención es el alarmismo que se desprende de los titulares de LV. Se avisa que el la prostitución "está fuera de control" (titular 2), que hay un "abismo en el Raval" (titular 14), que da mala imagen a la ciudad (titular 12,13 y 15). Otros titulares hacen referencia a las diferentes situaciones de las mujeres que ejercen la prostitución como "Mujeres sin papeles en el laberinto" (titular 3) o "Extorsión a la nigeriana" (titular 12), siendo más confuso a qué se refieren con el uso de metáforas tales como "callejón sin salida" (titular 8) o "Juego del ratón y el gato en la ronda de Sant Antoni" (titular 5) y que no se acaban de entender sin el texto que los acompaña. 


\subsection{Definición de inmigrante/prostituta}

A la hora de referirse a la mujer inmigrante que ejerce prostitución, encontramos en EP las siguientes apelaciones: "decenas de jóvenes subsaharianas" (1/09), "jóvenes africanas" (1/09), "víctimas de explotación" (1/09), travestidos latinoamericanos(1/09), "las prostitutas más degradadas de la ciudad", (1/09) "jóvenes inmigradas" (1/09), "muy jóvenes y agresivas" (1/09), "las putas más baratas" (1/09), "mujeres reincidentes"(2/09), en situación irregular "(2/09), "explotadas" (2/09), "extracomunitarias" (2/09 y (3/09), "que carecen de domicilio" (2/09), "prostitutas" (2/09), mujer en situación de vulnerabilidad (2/09), "sin papeles" (3/09), "inmigrantes irregulares sin identificar" (3/09), o "que son entregadas a la policía" (3/09), "trabajadoras" (3/09), "jóvenes nigerianas" (4/09), "jóvenes subsaharianas" (4/09), "Chicas" (4/09), "prostitutas en situación irregular"(5/09); “carecen de papeles, son madres y mantienen una familia" (6/09), "conscientes de que están en el centro del huracán pero no se les da voz" (6/09), "prostitutas africanas" (6/09), "meretrices" (6/09), "detenidas" (6/09), "sospechosos" (6/09), "extranjeras que no tengan papeles en regla" (11/09).

Por su parte, en LV encontramos definiciones similares de las mujeres que se dedican al trabajo sexual. En las piezas informativas se refieren a ellas como "prostitutas" (4/09), "mujeres subsaharianas implicadas en la Red de la Rambla" (4/09), "invasión" (4/09), "mujeres explotadas sexualmente" (4/09), "sometidas a una presión implacable de sus proxenetas" (4/09), "que carecen de documentación" (4/09), "problema" (4/09), "invasión" (4/09), "sin papeles" (4/09), "quedan al margen de la repatriación o de la reinserción" (4/09), "atrapada en el laberinto" (4/09); "expuestas a la explotación de los proxenetas" (4/09); "muchacha" (4/09), "sospechosa de vulnerar la Ley de Extranjería" (4/09), "indocumentados" (4/09), "ingresada en un centro de internamiento de extranjeros" (4/09), "la prostituta subsahariana es una mujer sin nombre que no puede ser expulsada pero tampoco reconocida por el por el país de acogida" (4/09), "meretriz" (4/09 y 6/09); "no puede ser retenida y siguen en la calle" (4/09), "repatriadas" (5/09), "detenidas" (5/09), "joven subsahariana" (5/09 y 9/09), "mujeres víctimas de redes de proxenetismo" (6/09), "desaparecidas" (6/09); "prostitutas nigerianas" (5/09, 6/09 y 9/09), "menos agresivas, más recatadas" (6/09); "extorsionada" (9/09), "víctimas de redes asentadas en el extranjero" (9/09), "explotadas" (9/09); "víctimas de grupos criminales que no están radicadas en España" (9/09), "mujeres completamente indocumentadas" (9/09), "entregadas por sus propios padres para el sustento familiar" (9/09), "jóvenes prostitutas" (8/09), "inmigrantes africanas sin papeles" (8/09), "prostitutas liberadas o ausentes" (8/09), "nigerianas $(8 / 09)$, "mujeres de vida" (10/09), "no son chicas de prostíbulo (8/09) y "esclavas sexuales (11/09).

En ambos diarios, se hace especial énfasis en el hecho de no estar regularizadas; se tratan, en resumen de "prostitutas sin papeles". Aparece la idea de que son mujeres atrapadas y que no tienen ninguna otra posibilidad que ejercer la prostitución. "La figura de estas mujeres queda atrapada en un laberinto en el que cuando son identificadas por la policía en la calle quedan retenidas en ocasiones durante horas, y cuando no puede probarse de dónde vienen se las devuelve a la plena libertad de movimientos y quedan otra vez expuestas a la explotación de proxenetas que las dirigen" (LV. 4/09). 


\subsection{Acciones realizadas por las inmigrantes/prostitutas}

En EP nos encontramos con: "No esperan a los clientes, sino que los buscan, los abordan y les plantan cara" (1/09), "Aún se ve alguna de las viejas trabajadoras por la calle Robadors, pero ya hace tiempo que la mayoría ha sido substituida por las jóvenes inmigradas que también roban y se pelean entre ellas por los clientes" (1/09), y "Tres jóvenes, también rumanas, han tratado de extorsionar a otras chicas por usar la calle. Éstas se han resistido con golpes de cinturón y tirones de pelo" (6/09). En LV encontramos: "Acusan e intimidan a los transeúntes en la Rambla sin ningún recato hasta convertir el paseo por esta avenida en una experiencia poco recomendable" (4/09), "Salen a la caza del turista borracho" (4/09), y "No se abalanzaron sobre potenciales clientes como era ordinario en la Rambla, al menos anoche- pero dejaron claro que iban a seguir en lo suyo (5/09).

En ambos diarios son vistas como agresivas y violentas, queremos destacar el detalle de que el cliente queda totalmente protegido en un segundo plano y sólo aparece mencionado para remarcar el comportamiento violento de la prostituta inmigrante.

Conviene también destacar que aunque siempre se habla de 'ellas' (mujeres inmigrantes que ejercen la prostitución) no será hasta el quinto día después de la aparición de las polémicas fotografías que EP se decide a dar voz al colectivo, si bien es cierto que lo que aparece es la desconfianza entre ellas: "Allí sobreviven prostitutas españolas, aunque la vía está dominada ahora por las rumanas. Éstas recelan de las subsaharianas y recuerdan que algunas abordan con violencia a los clientes y les hurtan la cartera" (6/09). En un claro ejemplo de doble estigmatización, son las mismas prostitutas (autóctonas) las encargadas de destacar las cualidades negativas de las 'otras' prostitutas: "Luego nos acusan a todas de lo mismo y cuesta más trabajar", se queja una que pasea en sujetador gris y pantalón corto por la calle, llegaron las nigerianas y reventaron precios" (6/09), "se desmarcan de los robos y las escenas de sexo en las callejuelas del Raval que protagonizan algunas de sus compatriotas" (6/09).

Un aspecto derivado del análisis de la categoría 'acciones realizadas por las inmigrantes/prostitutas' es el análisis de cómo se representa a 'ese otro sobre el que' la prostituta ejerce su acción, esto es, el cliente. En ambos diarios, son presentados desde un rol pasivo, como si no tuvieran responsabilidad en el desarrollo de la escena. Así, por ejemplo, leemos en EP: "No esperan los clientes, sino que los buscan, los abordan, y les plantan cara" (1/09) o "abordan a los turistas en torno a la calle de Robador" (1/09) u "otras aguardaban a sus clientes apostadas en las inmediaciones del lado de la montaña de la plaza de Catalunya" (3/09). La misma consideración la podemos encontrar en LV: "un grupo de tres prostitutas nigerianas se acerca a cuatro turistas que están sentados [...] Comienzan las proposiciones, aunque los turistas las ignoran. Ellas no desisten. Comienzan a ponerse más insistentes y alguna de ellas, apretando el trasero, trata de buscar sitio en el mismo banco" (6/09). El diario da un paso más allá al remarcar que los clientes (casi todos ellos turistas) están borrachos, ebrios o desfasados, cayendo en el recurso del alcohol como exculpatorio de responsabilidad personal. Así aparece un mensaje implícito: por una parte, es la prostituta inmigrante la que se dedica a 'cazar' al cliente que, además, es un 'turista'. Los autóctonos quedan libres de pecado: el mundo de la prostitución en la calle es ejercida por 'las otras' y se 
benefician 'los otros', en ambos casos 'vienen de fuera'. Algo que la propia LV parece querer destacar cuando en un artículo de opinión publica: "las prostitutas nigerianas volverán a la caza de turistas de borrachera de aquí te pillo aquí te mato".

\subsection{Acciones realizadas sobre las inmigrantes/prostitutas}

En EP se puede leer 5 :

"Traídas a Barcelona por mafias internacionales", "Muchas veces tengo que apartar la cara de la pantalla por el asco que siento", "Se quitan de en medio y aseguran que no es competencia suya perseguir la prostitución", "reclama espacios para que estas trabajadoras puedan abandonar la calle", "van a buscar prostitutas", y "parece que la policía las ha empujado hacia arriba" (1/09); "identifica y sanciona a las mujeres, la mayoría inmigrantes sin papeles", "las entrega al Cuerpo Nacional de Policía del Ministerio del Interior. Si las mujeres no son expulsadas de el país, ya no es cosa suya, sostiene", "eludió públicamente contestar a estas acusaciones del gobierno municipal, aunque recordó que no basta con la entrega de una inmigrante irregular sin identificar, porque esto imposibilita su expulsión a países del África subsahariana con los que no existe convenio de extradición", "partidarios de legalizar la prostitución para que las mujeres ejerzan en locales regulados", "piden una solución frente al aumento de la prostitución, con zonas en que el sexo se practica al aire libre", "La policía local puede realizar labores disuasorias", "Detiene a prostitutas debe ponerlas a disposición de la Subdelegación del Gobierno central", "El consistorio no puede, recordó, iniciar el proceso de expulsión", "El agente tampoco puede detenerla porque, a menos que esté practicando sexo delante de un menor, la prostitución no es delito", "incoamos el expediente de expulsión, pero muchas veces sus países no las reconocen y se quedan aquí", (2/09); "Los proxenetas que controlan a las mujeres (la mayoría extracomunitarias sin papeles) tratan de hacerse fuertes", "El Ayuntamiento de Barcelona mantuvo ayer sus críticas a la Delegación del Gobierno por no resolver los procedimientos de 683 prostitutas en situación irregular entregadas por la Guardia Urbana al Cuerpo Nacional de Policía. Menos del 1\% fueron finalmente expulsadas" (3/09); "Vacían la Rambla de prostitutas”, “¿Ésa es su solución? ¿Sacar a la policía a la calle para machacar a las chicas?" (4/09); "El problema de la prostitución no se puede resolver únicamente desde la vertiente policial, sino que se debe abordar de forma transversal", "El operativo [...] y busca detectar "focos de inseguridad ciudadana", "Identificar a las prostitutas que están en situación irregular en España", "La Federación de Asociaciones de Vecinos de Barcelona y diversas entidades que apoyan el derecho de las prostitutas a ejercer libremente pidieron ayer la derogación de la ordenanza de civismo por "ineficaz" y porque, a su juicio, ha precarizado las condiciones de trabajo de las mujeres" (5/09).

5 Por razones obvias de espacio se hace imposible poner la totalidad de los ejemplos recogidos y se ha optado por mostrar una selección de aquellas frases que mejor ilustran nuestro análisis 
Por su parte, en LV leemos:

"Un alto cargo de la Generalitat [...] llamó a la plana mayor de la policía autonómica y les conminó a acabar con la exhibición de prostitutas en las carreteras de Catalunya", "Es imposible poner coto a situaciones como las vistas en los últimos meses en la Rambla de Barcelona y que, de hecho, se repiten -sin aparente escándalo- en muchas carreteras catalanas", "El Ayuntamiento de Barcelona considera que una de las soluciones al problema que ahora tiene planteado en La Rambla es la expulsión de las mujeres", "El Ayuntamiento de Barcelona presiona en una zona, desplaza el problema hacia otro barrio", "Las redadas, que a menudo acaban con la puesta en libertad -disipan las redes, pero no lo resuelven definitivamente porque casi nunca, en estas pesquisas, caen los responsables que explotan a las mujeres", (4/09); "Hereu [...] se comprometió a mantener el tiempo que haga falta la presencia de los mossos y de la Guardia Urbana en la Boqueria [...] para contener el fenómeno"; "Colaboración con los cuerpos policiales para acabar con las redes internacionales que explotan a mujeres", "Escarp aseguró días antes que menos del 1\% de las meretrices que son conducidas a los centros de extranjería son repatriadas, lo que provoca que después de ser detenidas vuelvan rápidamente a las calles", "La presencia de prostitutas subsaharianas en la Rambla ha desaparecido casi por completo coincidiendo con el refuerzo policial de los Mossos de Esquadra y de la Guardia Urbana" (5/09).

Vemos que el actor principal de las acciones a las inmigrantes/prostitutas es la policía y los mossos d'esquadra ${ }^{6}$, ambos encargados de 'limpiar la zona', 'perseguirlas', 'ahuyentarlas', 'detenerlas y/o ponerlas a disposición de los cuerpos superiores para su posible repatriación'. Esta abundancia de los cuerpos policiales como protagonistas de la noticia también redunda en la asociación entre 'prostitución', 'inmigración' y 'delincuencia'. La imagen de prostituta inmigrante como víctima queda, en estos casos, diluida y la única referencia que hemos podido encontrar en nuestro estudio que refiera a la posible causa de su situación es la siguiente: "Los grupos nigerianos ejercen sobre sus víctimas una presión extrema llegando incluso a realizar rituales de vudú y hechicería tradicional para obligar a las mujeres a prostituirse y mantenerlas en un estado de auténtico terror" (LV, 9/09).

\section{Conclusiones}

Una de las principales conclusiones a las que llega nuestro estudio es que los diarios El País y La Vanguardia contribuyen a perpetuar estereotipos y a fomentar los prejuicios al redundar en la vinculación entre mujer inmigrante que ejerce la prostitución y delincuencia. Ambos diarios elaboran una representación de les prostitutas inmigrantes como personas agresivas, delincuentes que roban a los turistas, y que contribuyen a proyectar una imagen degradada de la ciudad. Además, la estrategia de polarizar el discurso diferenciando entre un 'nosotros' y un 'ellos' contribuye a culpabilizar a la víctima de su problema. Se establece de esta manera una asociación entre inmigración-prostitución-delincuencia-degradación que es muy difícil de romper y que inevitablemente se mantendrá en la mente del lector. La manera sesgada

${ }^{6}$ Mossos d'esquadra: Policía autonómica de Catalunya. 
como los dos diarios han tratado el caso del Raval pone de manifiesto una vez más la visión reduccionista y simplista de una compleja realidad que es explicada poniendo el énfasis en los problemas y sin tener en cuenta su situación de enorme vulnerabilidad, tan sólo mencionada en contadas ocasiones.

En una clara dicotomía entre los buenos y las peligrosas, tenemos, por un lado, un colectivo instaurado en la ilegalidad por su lugar de origen y por sus acciones y, en el otro, un grupo de actores sociales encargados de ejercer el bien. $Y$ en medio, nos encontramos con lo que en apariencia parecen ser presentados como las auténticas víctimas de la situación: los turistas-clientes.

En lo que se refiere a la categoría analizada de 'acciones realizadas sobre a las mujeres inmigrantes-prostitutas", el análisis nos ha desvelado la gran cantidad de acciones que tienen que ver con el mensaje de mantener el orden público (intensificando la vigilancia policial, agilizando los trámites de legalización y posterior expulsión, deteniendo, prohibiendo) de forma incluso 'bélica' (perseguir, combatir, luchar contra, ejecutar las órdenes de expulsión) lo que lleva a redundar en la idea de la prostitución como problema, falta de civismo y generadora de inseguridad ciudadana. Son ellas las que vulneran la ley y provocan problemas de convivencia. Son ellas las culpables de su situación. El discurso imperante de vincular la inmigración y la delincuencia inevitablemente acaba llevando a la criminalización del colectivo. Pero, además, el discurso de la prostituta como culpable convive, paradójicamente, con la imagen de las mujeres que ejercen la prostitución como mujeres perdidas y desviadas de las normas. Esta mirada esconde, de una parte, la multiplicidad de situaciones alrededor de las mujeres que se dedican al trabajo sexual y, por otra parte, dificulta que se adopte una regulación sobre la prostitución.

El reto seria conseguir que los medios de comunicación fueran conscientes de la enorme responsabilidad que tienen a la hora de informar sobre la prostitución. Y parte de esta conciencia pasaría, creemos, por reconocer no solo la situación de especial vulnerabilidad de los colectivos de personas inmigrantes, sino también la vulnerabilidad de las mujeres que ejercen la prostitución, especialmente cuando no tienen sus derechos reconocidos. Sólo de esta forma se podrá informar desde el rigor y el respeto, evitando una visión negativa y estereotipada.

\section{Referencias bibliográficas}

AGUSTÍN, Laura M $\mathrm{M}^{\mathrm{a}}$ (2006): "Atreverse a cruzar fronteras: migrantes como protagonistas”. Viento Sur, 87, pp. 73- 82. http://www.vientosur.info/articulosabiertos/vientosur87-plural-prostitucion-LauraAgustin.pdf [fecha de consulta: 26 de septiembre de 2011]

AGUSTÍN, Laura Ma (2004): Trabajar en la industria del sexo, y otros tópicos migratorios. Donosti, Gakoa Liburuak.

DIJK, Teun A. van (2006): De la Gramática del texto al Análisis Crítico del Discurso. Una breve autobiografia académica. En: http://www.discursos.org/cv/De\%201a $\% 20$ gramatica $\% 20$ del $\% 20$ texto $\% 20$ al $\% 20$ analisis $\% 20$ critico $\% 20$ del $\% 20$ discurso.pdf [fecha de consulta: 26 de septiembre de 2011] 
GIRÓ, Xavier y JARQUE, José Manuel (2006): “Prensa escrita e inmigración: Estudio sobre la opinión de los diarios sobre la inmigración procedente de fuera de la Unión Europea y sobre la cobertura informativa de conflictos destacados que tienen relación con ella (Octubre 1999-Junio 2002)”. Zer, 20, pp. 251- 270.

HOLGADO, Isabel (2004): “A vueltas con la prostitución”. Athenea Digital. Revista de Pensamiento e Investigación Social, 5. En: http://psicologiasocial.uab.es/athenea/index.php/atheneaDigital/article/viewArticle/138/138 [fecha de consulta: 26 de septiembre de 2011]

HOLGADO, Isabel (2001): "Las nuevas retóricas de la inmigración femenina: la prostitución en las calles de Barcelona". Scripta Nova, 94. En: http://www.ub.edu/geocrit/sn-94-100.htm [fecha de consulta: 26 de septiembre de 2011]

IGARTÚA, Juan José, HUMANES, Mª Luisa, MUÑIZ, Carlos et al. (2004): La información sobre inmigración e inmigrantes en la prensa española. ¿Barreras mediáticas a la integración o imágenes que generan xenofobia. Comunicación presentada en el Diálogo Comunicación y Diversidad Cultural Forum 2004, Barcelona, del 24 al 27 de mayo de 2004. En: http://www.portalcomunicacion.com /dialeg/paper/pdf/110_igartua.pdf [fecha de consulta: 26 de septiembre de 2011]

JULIANO, Dolores (2005): "Les altres dones. La construcció de l'exclusió social. Els discursos que ens uneixen i ens separen”. Barcelona, Institut Català de les dones, Quaderns de l'Institut.

JULIANO, Dolores (2001): La prostitución, el espejo oscuro. Barcelona, Icaria.

JULIANO, Dolores (1998): Las que saben. Subculturas de mujeres. Madrid, Horas y Horas.

McCOMBS, Maxwell (2006): Estableciendo la agenda. El impacto de los medios en la opinión pública y en el conocimiento. Barcelona, Paidós Comunicación.

MUÑIZ, Carlos y IGARTÚA, Juan José (2004): "Encuadres noticiosos e inmigración. Un análisis de contenido de la prensa y televisión españolas". Zer, 16, pp. 87104.

PEDONE, Claudia (2001): "La inmigración extracomunitaria y los medios de comunicación: la inmigración ecuatoriana en la prensa española". Scripta Nova: Revista Electrónica de Geografia y Ciencias Sociales. En: http://www.ub.edu/geocrit/sn94-43.htm [fecha de consulta: 26 de septiembre de 2011]

RODRIGO ALSINA, Miquel (2006): "El periodismo ante el reto de la inmigración", en: LARIO, Manuel (coord.): Medios de comunicación e inmigración. Murcia, Gallegraf, pp. 37-58. 


\section{Anexo 1: ejemplos aplicados de ficha analítica}

\begin{tabular}{|c|c|}
\hline \multicolumn{2}{|c|}{ Titular T12: Huida por el Eixample (El País, 03/09/2009) } \\
\hline Lugar geográfico & \\
\hline Espacios físicos & $\begin{array}{l}\text {-Eixample } \\
\text {-la Rambla de Catalunya } \\
\text {-Calle Diputació }\end{array}$ \\
\hline Espacios temporales & -durante la madrugada del pasado miércoles \\
\hline Actores protagonistas de la noticia & $\begin{array}{l}\text {-prostitutas subsaharianas } \\
\text {-clientes } \\
\text {-policía }\end{array}$ \\
\hline Definición inmigrante/prostituta & $\begin{array}{l}\text {-trabajadoras } \\
\text {-una rumana }\end{array}$ \\
\hline $\begin{array}{l}\text { Acciones realizadas por las inmigran- } \\
\text { tes/prostitutas }\end{array}$ & $\begin{array}{l}\text {-Un grupo de decenas de prostitutas subsaharianas HUÍA corriendo } \\
\text { durante la madrugada del pasado miércoles por la Rambla de } \\
\text { Catalunya y la calle Diputació, que estas trabajadoras no sue- } \\
\text { len pisar. } \\
\text {-Otras AGUARDABAN a sus clientes apostadas en las inmedia- } \\
\text { ciones del lado de la montaña de la plaza de Catalunya } \\
\text { - se refugiaron en la zona noble del Eixample" }\end{array}$ \\
\hline $\begin{array}{l}\text { Acciones realizadas sobre las inmi- } \\
\text { grantes }\end{array}$ & \\
\hline
\end{tabular}

